Article

\title{
Accident Rate as a Measure of Safety Assessment in Polish Civil Engineering
}

\author{
Wieslawa Cieslewicz ${ }^{1}$, Krystyna Araszkiewicz ${ }^{1, *}$ and Pawel Sikora ${ }^{1,2}$ (D) \\ 1 Faculty of Civil Engineering and Architecture, West Pomeranian University of Technology, al. Piastow 50, \\ 70-311 Szczecin, Poland; wieslawa.cieslewicz@zut.edu.pl (W.C.); pawel.sikora@zut.edu.pl (P.S.) \\ 2 Building Materials and Construction Chemistry, Technische Universität Berlin, Gustav-Meyer-Allee 25, \\ 13355 Berlin, Germany \\ * Correspondence: krystyna.araszkiewicz@zut.edu.pl; Tel.: +48-91-449-48-14
}

Received: 30 July 2019; Accepted: 22 October 2019; Published: 30 October 2019

\begin{abstract}
Civil engineering is characterised by high volatility with respect to working conditions, which are the source of many threats to worker life and health and contribute to high accident rates. The purpose of this paper is to analyse and evaluate the phenomenon of accidents in Polish civil engineering and define the direction of changes that should occur in the safety area. The studies included in this research covered the years 2004-2018. The following indicators were used to assess the accident rates: (1) The total number of persons injured in workplace accidents and this total divided into fatal, severe, and minor accidents; (2) indicators of frequency of accidents in total and this total divided into minor, severe, and fatal accidents; (3) and an indicator of the severity of accidents. From the analysis of statistical data for the years 200-2018, the changes in accident rate parameters demonstrate the continuous improvement of workplace safety in the Polish civil engineering sector. From the analysed data from the 15 years, a clear decrease in the value of the applied indicators is apparent, including both the number of people involved in accidents and the frequency and severity of accidents.
\end{abstract}

Keywords: civil engineering; accident rates; workplace accident; workplace safety

\section{Introduction}

Security can be defined as the absence of danger in the lives of individuals and collectives and is related to values such as life, health, property, environment, civil rights and freedoms, social life, and spiritual and intellectual property. Security is one of the most important human needs and is therefore subject to special protection. The right to security is an inalienable human right, and the state, as a form of organisation of social life, should safeguard it.

Workplace safety is influenced by many factors, including technical and organisational conditions in companies, adaptation of working-environment conditions to the abilities of employees, and people's attitudes towards safety and health issues. Improper working conditions often lead to harm, such as death or serious bodily injury, occupational disease and material damage. For this reason, workplace safety often determines the success of a business [1].

Civil engineering is a sector of the economy characterised by high volatility of working conditions, which are a source of many threats to worker life and health and contribute to high accident rates [2-5]. The subject of workplace safety in the civil engineering sector requires defining the very essence of this sector. Pursuant to the Regulation of the Council of Ministers of 20 January 2004 on the Polish Classification of Business Activities (PKD) [6], it covers the construction of complete building structures and works involving rebuilding, expansion, reconstruction, repair, modernisation, maintenance and use of permanent and temporary building structures. High accident rates are favoured by the specifics of 
work in the civil engineering sector resulting from such factors as diversity of processes, a large number of equipment presenting hazards, frequent change of location of project sites and changing working conditions on individual construction sites, the presence of many subcontractors on one construction site, a high turnover of workers, the impact of weather conditions. The statistical data confirm this. In 2017, the European Union recorded that 3000 people were injured in workplace accidents per 100,000 employees in the civil engineering sector. There were 1100 accidents on construction sites every day. Other countries around the world exhibit similar situations. For instance, in the United States, the accident rate in the civil engineering sector is three times higher than in other sectors of the economy [2]. Also, in Poland, statistical data on accident rates confirm the importance of the problem of workplace safety in the construction sector. Table 1 presents data on the number of injured people and the frequency of accidents per 1000 persons employed in the national economy in 2018.

Table 1. Number of injured people and frequency of workplace accidents in specific sectors of the Polish national economy in 2018 [7].

\begin{tabular}{|c|c|c|c|c|}
\hline $\begin{array}{l}\text { Section } \\
\text { Symbol }\end{array}$ & Section Name & $\begin{array}{l}\text { Number of } \\
\text { Victims }\end{array}$ & $\begin{array}{l}\text { \% Share of } \\
\text { Victims }\end{array}$ & $\begin{array}{c}\text { Accident } \\
\text { Frequency Rates }\end{array}$ \\
\hline A & Farming, forestry, hunting and fishing & 1143 & 1.36 & 6.37 \\
\hline B & Mining and extraction & 2244 & 2.66 & 14.73 \\
\hline $\mathrm{C}$ & Industrial processing & 28,669 & 34.00 & 10.14 \\
\hline $\mathrm{D}$ & $\begin{array}{l}\text { Generation and supply of electricity, gas, } \\
\text { steam and hot water }\end{array}$ & 636 & 0.76 & 5.71 \\
\hline $\mathrm{E}$ & $\begin{array}{c}\text { Water supply, sewerage, waste management, } \\
\text { remediation }\end{array}$ & 2263 & 2.68 & 14.25 \\
\hline $\mathbf{F}$ & Civil engineering & 5247 & 6.22 & 6.02 \\
\hline G & Commerce, repair of motor vehicles & 10,906 & 12.93 & 4.55 \\
\hline $\mathrm{H}$ & Transport and warehouse management & 6885 & 8.16 & 7.95 \\
\hline I & Accommodation and gastronomy & 1152 & 1.37 & 4.06 \\
\hline $\mathrm{J}$ & Information and communication & 462 & 0.55 & 1.32 \\
\hline K & Financial and insurance business & 811 & 0.96 & 2.16 \\
\hline $\mathrm{L}$ & Real estate services & 827 & 0.98 & 4.0 \\
\hline M & Professional, scientific and technical activities & 1167 & 1.38 & 1.9 \\
\hline $\mathrm{N}$ & Administration and support activities & 3749 & 4.45 & 6.59 \\
\hline $\mathrm{O}$ & $\begin{array}{l}\text { Public administration and national defence, } \\
\text { compulsory social security }\end{array}$ & 3495 & 4.15 & 5.28 \\
\hline $\mathrm{P}$ & Education & 4420 & 5.24 & 3.75 \\
\hline Q & Health care and social work activities & 8858 & 10.51 & 10.00 \\
\hline $\mathrm{R}$ & Entertainment and recreation activities & 873 & 1.04 & 5.65 \\
\hline $\mathrm{S}, \mathrm{T}, \mathrm{U}$ & Other service activities & 497 & 0.60 & 1.75 \\
\hline
\end{tabular}

As the above figures show, in 2018, 84,304 employees in the whole economy were affected, including 5247 in the civil engineering sector. The accident frequency index for the whole economy was 6.37 and for the civil engineering sector was 6.02. The construction industry is fifth among all sections of the economy in terms of number of people injured in workplace accidents and eighth in terms of frequency of accidents. These results are better than in previous years, indicating an improvement in workplace safety, but are still unsatisfactory.

The aim of this study is to analyse and evaluate the accident rate phenomenon in the Polish civil engineering sector and to determine the direction of changes occurring in the area of safety in this 
section of the economy. Accident rate is a mass phenomenon, and so the level of safety and noticeable tendencies is determined not by a single event, but rather by a set of accidents that occur in a given period of time. In order to achieve this goal, it was necessary to develop a research methodology and undertake the following actions:

1. Gather statistical data published by the Central Statistical Office in Poland on the number of victims of workplace accidents in total and divided into minor, severe and fatal accidents; the frequency of accidents per 1000 employees; and the number of days of incapacity to work per one employed person;

2. Develop indicators for evaluating the phenomenon under investigation;

3. Analyse and evaluate the accident rates by means of development trends models; and

4. Formulation of final conclusions.

\section{Literature Review}

Problems of safety in the construction industry and methods of controlling and monitoring the level of safety on construction sites are undertaken by many authors, focusing their research on a wide variety of safety-related issues, which may be a hindrance to the review of this field. However, such an attempt should be made, because a systematic review of previous research works facilitates the exchange of useful research results and makes it possible to orientate in the forecasted trends in research on construction safety.

Such a review was carried out, inter alia, by Zhou, Goh and Li, determining the division of research on construction safety into three main groups [8]. The first of these groups is research conducted from the point of view of the safety management process, while the second group focuses on examining the impact of individual and group characteristics such as employee behaviour, perception and safety climate in relation to safety in construction. The third group uses and analyses the accident/event data to improve safety performance. This article is part of the scope of this research group [8].

From the strategic perspective concerning the management of the construction project and safety at the construction site, it can be stated that the subject of dynamically developing research direction in recent years is associated primarily with the use of digital techniques and their impact on the effectiveness of the systems protecting the health and safety of construction workers during the work and ahead of time, at the planning stage of the project [9]. In this group, many publications present the results of research related to the building information modelling method (BIM) [10-12]. The use of the data set gathered in the BIM model facilitates the combination of knowledge about construction risk and planning of security management [13]. The authors point to the possibility of early forecasting and combining knowledge related to work safety with information derived from the BIM model, for example for the purposes of automating the analysis of job hazard analysis (JHA) [14-16]. It is proposed to use the BIM model for the purpose of identifying hazards at the entire facility in individual stages of its construction, with the possibility of updating and monitoring the safety status using an automated information platform [17].

In the second group of studies, issues related to the creation of a safety culture at the construction site and a climate of safety are undertaken $[18,19]$. The role of safety leaders in shaping the approach to safety among employees of both the investor and contractors as well as works subcontractors is underlined. It can be additionally strengthened in the situation when safety leaders representing individual participants of the investment process work closely together [20]. Research also indicates the importance of attitude and behaviour of managers running teams carrying out construction works for the safety perception of construction workers. The attitude of managers towards safety issues, their behaviour in everyday work, compliance with health and safety rules can create a pattern of good practice and build a positive attitude among employees [21]. The dynamics and complexity of the construction industry means that the safety culture in a given project that differs from the others. Therefore, attempts are made to objectify the measurement of the state of safety culture in construction 
projects, for example by means of an indicator of a safety culture developed using the fuzzy set theory. For its calculation, it is proposed to use data on six categories of safety culture, such as management commitment, responsibility, employee engagement, supervisory leadership, communication, education and safety training [22].

In the third research group, one of the interesting proposals on how to measure safety is a set of 32 leading safety indicators in construction, developed on the basis of a safety model specific to the construction industry. The set includes, among others, indicators referring to different areas of the safety map, such as variability of working conditions, physical hazards or safety motivation among employees [23]. A significant part of research focuses on the construction market at a national scale, often taking into account the global context of this sector of the economy. Jo et al. conducted a study of the effects of accidents in construction in Korea in 2011-2015, using trend analysis. In order to analyse the characteristics of construction accidents, they used incidence rates (IRs) and mortality (MRs). After their calculation they carried out $\mathrm{T}$ tests and ANOVA analysis to establish the relationship between IR, MR and selected categories such as gender, age of employees or company size [24]. Kang et al. investigated the frequency and trend of fall-related accidents on the basis of analysis of 20,997 accidents that occurred in the construction industry in the United States in 1997-2012, registered in the Safety and Health at Work Administration (OSHA) database [25].

The subject of interest of researchers in recent years is also the method of measuring the quality of the safety climate, understood as the perception of safety in the workplace by employees. The proposed indicators are general or specific for a given type of work or industry [26,27].

In addition to traditional safety indicators, the literature presents complementary economic measures of health and safety at work using the cost-benefit analysis method [28,29]. Researchers point to the limitations of the approach using the cost-benefit analysis, because of the basic problems related to uncertainty, valuation, scope of analysis and quantification of benefits and costs [30].

Another prospective approach refers to the research using forecasting combining safety assessment techniques with risk analysis and assessment. In this approach, by means of various models, for example using artificial neural networks, future changes in the safety situation in a given construction company are foreseen. The innovative method presented in this group of research is structural equation modelling (SEM), enabling analysis and assessment of cause and effect relationships, e.g., phenomena such as safety culture and safety in the organisation or the impact of temporary employment on the level of safety at construction site [31-34].

Another important point is that the use of indicators calculated on the basis of historical data has been criticised by some researchers, who state that the result indicators provide little information on the causes of the accidents [35]. These indicators may reflect safety levels in a reactive way and help to set safety objectives, but do not provide information that would help to achieve the safety goals [36,37]. Proactive security management requires forecasting rather than post factum analysis. Relying on data from accident registrars may not give an insight into the complexity of the relationship between the factors contributing to these accidents, while forecasting requires an in-depth understanding of the complex safety phenomenon [38]. Despite the critical attitude of some researchers to conducting analyses using historical data and statistical methods, it should be emphasised that the use of statistical material gives analytical capabilities, through which it is possible to identify the causes of accidents in construction and design preventive activities and promoting safety culture on the site.

\section{Materials and Methods}

Statistical data of the Polish Central Statistical Office concerning the population of people employed in the civil engineering sector who have suffered a workplace accident were used for research purposes [7]. In accordance with the Social Insurance Act for Workplace Accidents and Occupational Diseases [39], a workplace accident is defined as a sudden event, caused by an external cause and resulting in an injury or death, that occurs: 
- During or in connection with the employee's normal activities or instructions from his/her supervisors;

- During or in connection with the performance by the employee of activities for the employer;

- Even without instructions;

- While the employee is at the employer's disposal, on the way between the employer's registered office and the workplace where the obligation arising out of the employment relationship is to be performed.

In respect of entitlement to benefits, workplace accidents are treated equally to accidents involving inter alia:

- During travel on official duty, unless the accident has caused conduct by an employee which is outside the scope of his employment duties;

- When carrying out tasks assigned by trade union organisations operating at the employer's premises.

Workplace accidents are also treated as equal to accidents sustained by an employee on the way to or from work and on the way to or from the place of work:

- Other employment or activity covered by the pension insurance scheme;

- The normal exercise of professional or social functions or tasks;

- The consumption of meals;

- Study or university studies.

In Poland, workplace accidents have been classified as minor, severe and fatal [39]. A minor accident is an event that is not classified in the other two categories, irrespective of the number of days of sickness-related absence of an employee, but which meets the definition of an accident.

A severe workplace accident results in serious bodily injury, e.g., loss of vision, hearing, speech, childbearing ability, a health disorder that affects the basic functioning of the body, incurable or life-threatening illness, permanent mental illness, total inability to work in the profession or permanent deformation or disfigurement of the body. Whether an accident is to be classified as severe is determined by the occupational health examiner. A fatal accident is one which results in the death of an injured employee within a period not exceeding 6 months from the date of the accident.

The studies involved in this research covered the years 2004-2018. The assumed time interval concerned 15 annual periods $i=1, \ldots, 15$. Historical data presented in the statistical yearbooks of the Central Statistical Office were used in the study [7]. The year 2004 was adopted as the beginning of the analysed data set, because of the time of Poland's accession to the EU and the commencement of implementation into Polish law of the provisions referred to in many EU directives covering various areas of work safety. The survey was completed on data from 2018, which were the last available data from the analysed statistical yearbooks of the Central Statistical Office. The following measures were used to assess the accident rate in the civil engineering sector:

- The number of persons injured in workplace accidents in total and divided into fatal, severe and minor accidents;

- Indicators of the frequency of accidents in total and divided into minor, severe and fatal accidents;

- Accident severity indicator.

The choice of such measures for the purposes of the survey was decided by two reasons:

- It was established on the basis of the analysis of available literature and professional practice of the authors that most accurately characterize the phenomenon and are commonly used by other researchers;

- the availability of complete data needed to calculate the indicators was determined by exploring the statistical yearbooks of the Central Statistical Office. 


\subsection{Number of Employees Injured by Workplace Accidents in Civil Engineering}

The number of employees who have had a workplace accident in the time period $t_{i}$ is presented using the following two formulae:

$$
\mathrm{PP}_{\mathrm{i}}=\sum_{\mathrm{w}=1}^{\mathrm{N}} \mathrm{lp}_{\mathrm{i}, \mathrm{w}}
$$

where:

$\mathrm{PP}_{\mathrm{i}}-$ number of employees involved in workplace accidents in the year $\mathrm{t}_{\mathrm{i}}$, $\mathrm{lp}_{\mathrm{i}, \mathrm{w}}$-number of persons injured in an accident in the year $\mathrm{t}_{\mathrm{i}}, \mathrm{w}=1, \ldots, \mathrm{N}$,

and,

$$
\mathrm{PP}_{\mathrm{i}}=\sum_{\mathrm{r}=1}^{3} 1 \mathrm{p}_{\mathrm{i}, \mathrm{r}}
$$

where:

PP $i$-number of employees involved in workplace accidents in the year $t_{i}$,

$\mathrm{lp}_{\mathrm{i}, \mathrm{r}}$-number of employees injured in category $\mathrm{r}$,

$=1$ minor accidents, $\mathrm{r}=2$ severe accidents, $\mathrm{r}=3$ fatal accidents.

\subsection{Workplace Accident Frequency Indicator}

This indicator gives the number of employees injured in accidents per 1000 persons employed in civil engineering in the year $t_{i}$. It is expressed as a correlation:

$$
\mathrm{m}_{\mathrm{i}, \mathrm{w}, 1000}=\frac{\mathrm{lp}}{\mathrm{i}, \mathrm{r}} \cdot 1000
$$

where:

$1 p_{i, r}$-number of people injured in workplace accidents in the year $t_{i}$,

$\mathrm{i}=1, \ldots, \mathrm{N} ; \mathrm{r}=1, \ldots, 4$,

$r=1$ minor accidents, $r=2$ severe accidents, $r=3$ fatal accidents, $r=4$ accidents altogether,

$l z=$ number of persons employed in civil engineering in the year $t_{i}$.

\subsection{Accident Severity Indicator for Workplace Accidents}

This indicator defines the number of days of sick leave per one person injured in minor and severe accidents and is expressed in the following formula:

$$
\mathrm{mc}_{\mathrm{i}}=\frac{\sum_{\mathrm{r}=1}^{2} \sum_{\mathrm{l}=1}^{\mathrm{l} \mathrm{p}_{\mathrm{i}, \mathrm{r}}} \mathrm{zl}_{\mathrm{i}, \mathrm{l}}}{\sum_{\mathrm{r}=1}^{2} \mathrm{l}_{\mathrm{i}, \mathrm{r}}}
$$

where:

$\mathrm{i}=1, \ldots, \mathrm{N} ; \mathrm{r}=1,2$,

$\mathrm{zl}_{\mathrm{i}, \mathrm{l}}$-number of days of sick leave per one employee who has had a minor or severe accident in the period $t_{i}$,

$l p_{i, r}=$ number of people injured in workplace accidents in the year $t_{i}$.

In order to present the changes occurring in each of the analysed phenomena and to determine the regularities which characterize them, two models of development trends were developed. The first model is a linear trend function that describes a first-degree polynomial, and it shows the general developmental trend in the analysed period of time. The second model is a trend function described by a fifth-degree polynomial, and it represents an attempt to illustrate the changes occurring in a given phenomenon in particular periods of the considered time frame. The degree of polynomial in the 
second model was selected experimentally by analysing the match of the obtained trend lines with the baseline data set.

In order to estimate and determine the trend line for the collected data, the method of least squares of errors was used. This is one of the oldest and most important calculation methods used in statistics. The parameters, which make it possible to determine the analytical form of the trend function unequivocally, were determined using MATLAB R2017b software. This software was also used to develop graphs illustrating the analysed phenomena with the trend lines plotted on them.

The method of least squares is particularly sensitive to deviations from the average, which can cause the greatest error. Even a single distorted observation, distant from the rest, will attract the trend line to itself. In the analysed phenomena, it cannot be ruled out that the collected data were subject to a certain error; however, the impact should be relatively small.

\section{Results}

\subsection{Number of Employees Injured by Workplace Accidents in Civil Engineering}

Figures 1-4 show the trends in the number of employees injured in workplace accidents in the years 2004-2018. The fifth-degree polynomial well describes the studied phenomena. In all types of workplace accidents, the trend line in the form of the first-degree polynomial shows a downward trend.

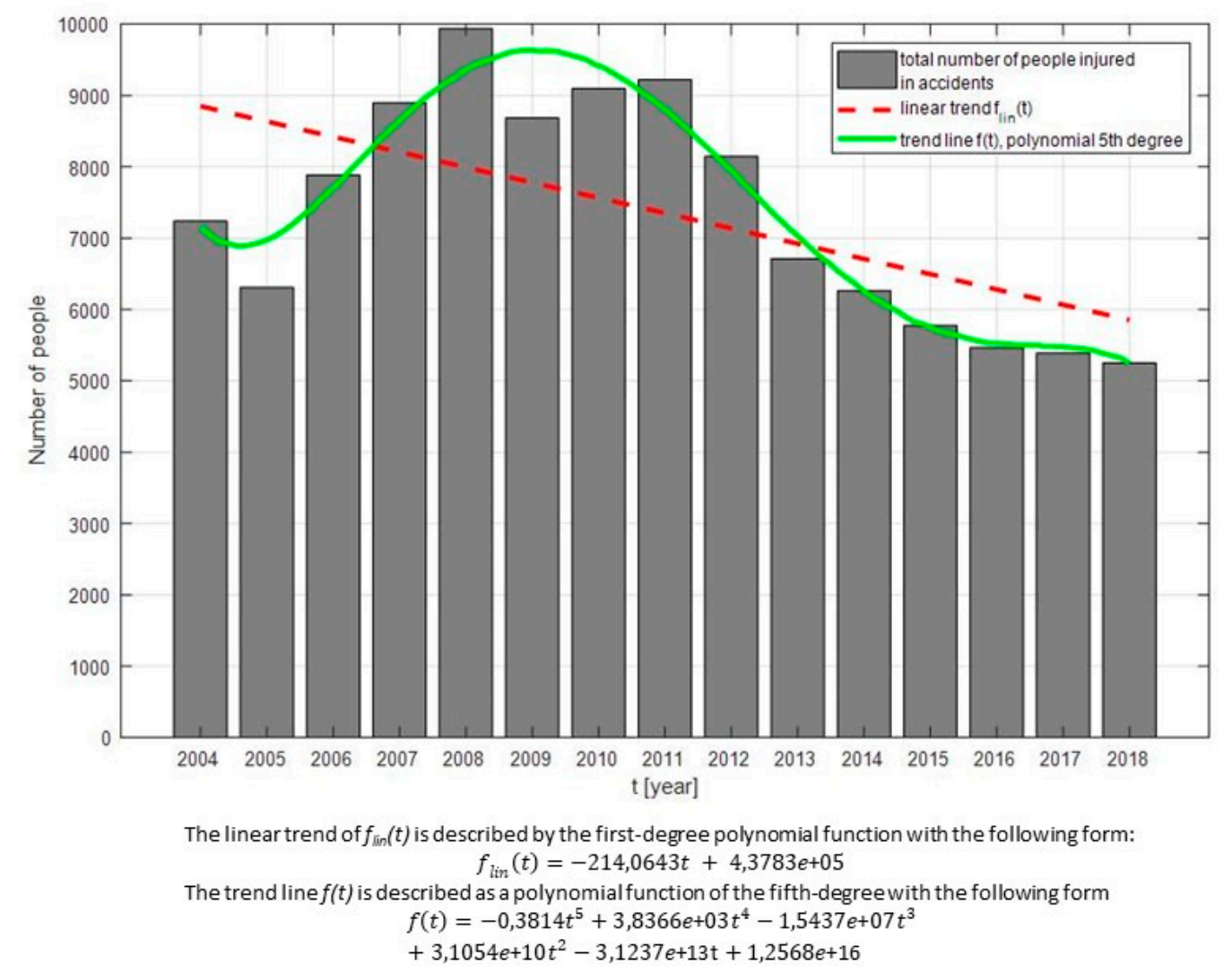

Figure 1. Trends in the total number of civil engineering workers injured by workplace accidents over time. 


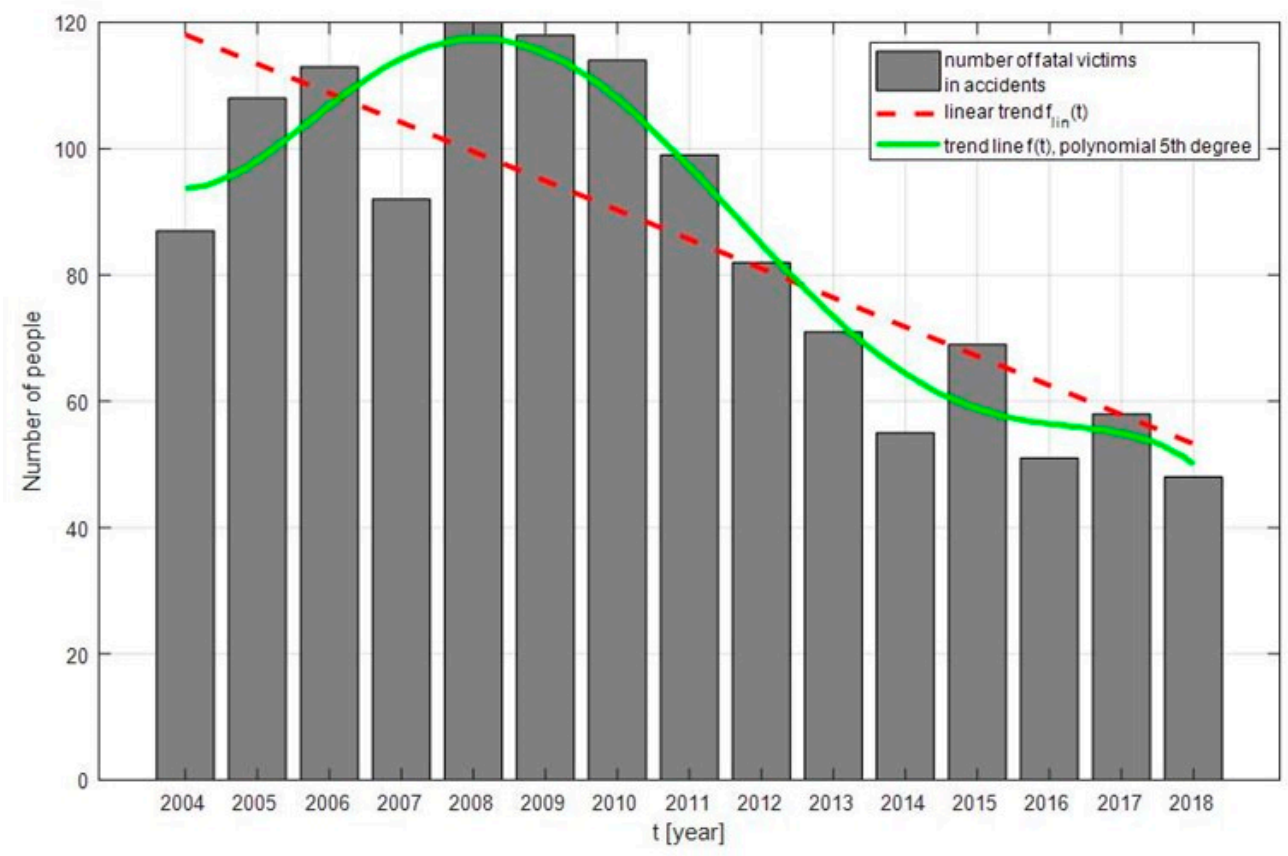

The linear trend of fin $(t)$ is described by the first-degree polynomial function with the following form $f_{\text {lin }}(t)=-4,6286 t+9,3937 e+03$

The trend line $f(t)$ is described as a polynomial function of the fifth-degree with the following form $f(t)=-0,0039 t^{5}+39,4353 t^{4}-1,5863 e+05 t^{3}$ $+3,1903 e+08 t^{2}-3,2082 e+11 t+1,2905 e+14$

Figure 2. Trends of changes in the number of fatally injured civil engineering workers over time.

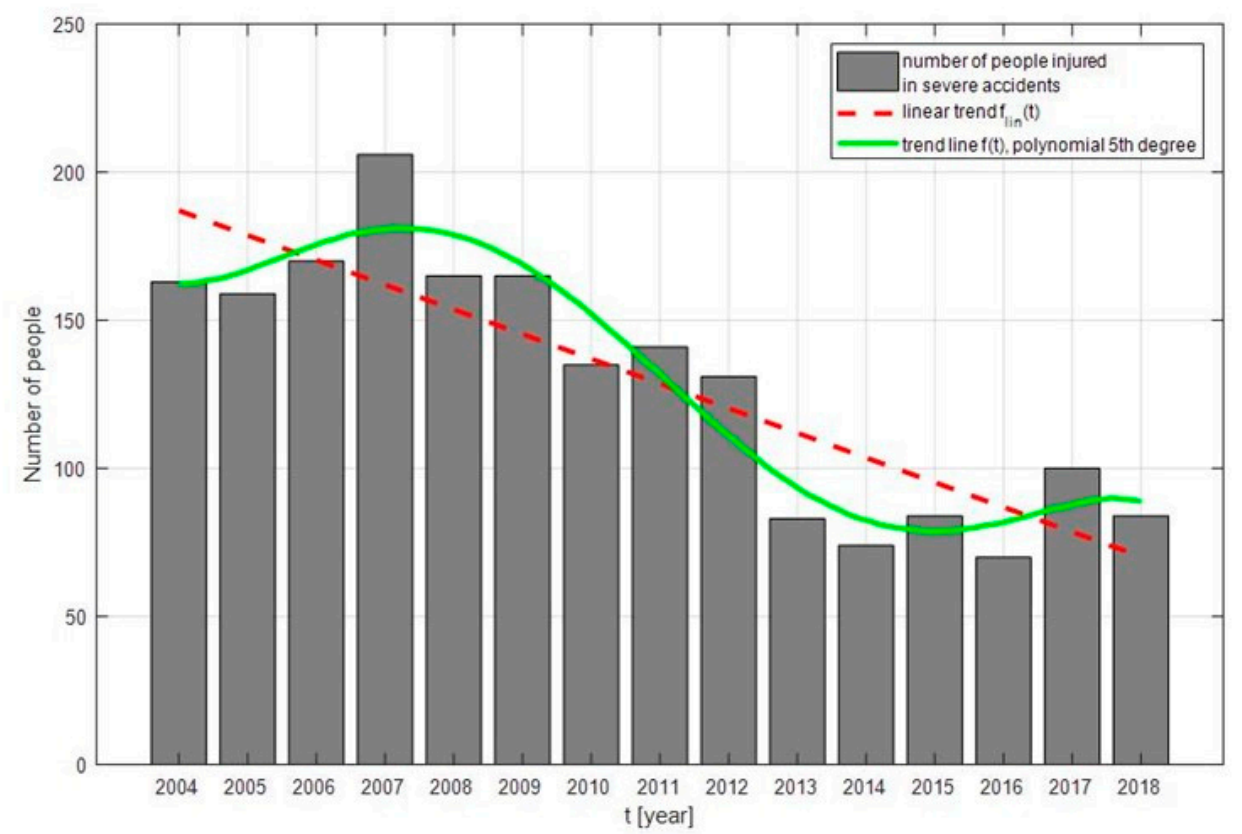

The linear trend of $f_{\text {in }}(t)$ is described by the first-degree polynomial function with the following form

$$
f_{\operatorname{lin}}(t)=-8,3429 t+1,6906 e+04
$$

The trend line $f(t)$ is described as a polynomial function of the fifth-degree with the following form

$$
\begin{gathered}
f(t)=-0,0062 t^{5}+62,0095 e+03 t^{4}-2,4940 e+05 t^{3} \\
+5,0154 e+08 t^{2}-5,0430 e+11 t+2,0283 e+14
\end{gathered}
$$

Figure 3. The evolution over time of the number of civil engineering workers injured in severe accidents. 


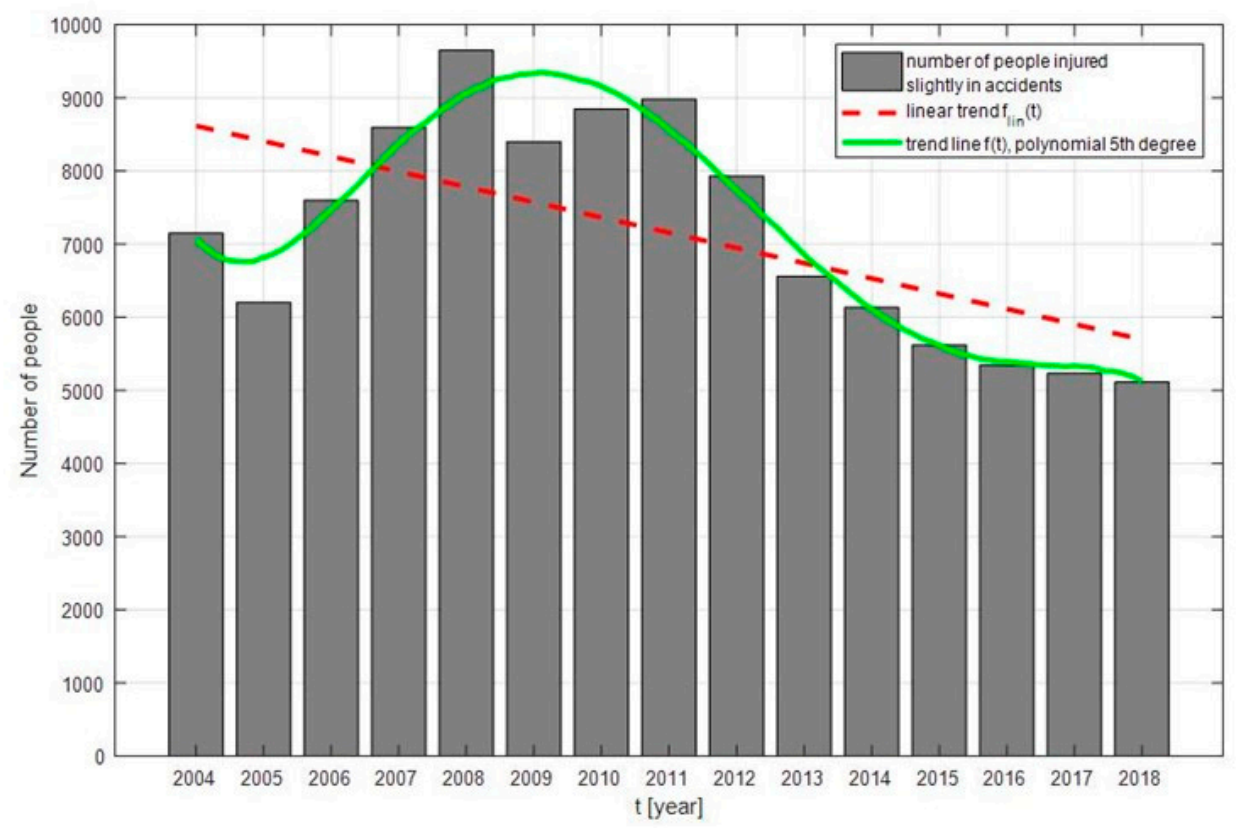

The linear trend of $f_{\text {inn }}(t)$ is described by the first-degree polynomial function with the following form $f_{\text {lin }}(t)=-208,5643 t+4,2658 e+05$

The trend line $f(t)$ is described as a polynomial function of the fifth-degree with the following form

$$
\begin{gathered}
f(t)=-0,3696 t^{5}+3,7174 e+03 t^{4}-1,4957 e+07 t^{3} \\
+3,0091 e+10 t^{2}-3,0268 e+13 t+1,2179 e+16
\end{gathered}
$$

Figure 4. Trends of changes in the number of civil engineering workers slightly affected by workplace accidents over time.

Figure 1 shows that, in the analysed period, the total number of people injured in accidents changed periodically in an increasing and decreasing way. The highest value of this indicator, amounting to 9937 workers affected, was observed in 2009. Since 2012, there has been a clear decrease in the total number of people who have suffered an accident in the course of their occupational activities. The lowest number of injured persons was registered in 2018. Compared to 2004, the decrease amounted to $52.8 \%$.

The number of fatalities of workplace accidents shown in Figure 2 shows a similar pattern of change. The trend increases and then decreases. The largest number of deaths were registered in 2008, and the number amounted to 120 . Between 2008 and 2018, a 60\% decrease in the number of fatal accidents was observed.

On the other hand, Figure 3 shows that, in accidents classified as severe, a growing trend was observed in the years 2004-2007 but decreased from 2008 onwards. The highest number of injured persons in the period analysed was registered in 2007; it concerned 206 employees. In 2018, this number fell to 84 .

Figure 4 shows that, the evolution of the number of employees injured slightly in workplace accidents increased until 2008 and clearly decreased from 2011 onwards. The highest number of victims in this category of accidents was recorded in 2008, when it reached 9652, and the lowest-5115-in 2018. The reduction in the number of workers affected between 2008 and 2018 amounted to $47 \%$.

In all the investigated types of workplace accidents in the Polish civil engineering sector, a significant decrease in the number of injured persons was recorded. Comparing years 2004 and 2018 , there was a $37.5 \%$ decrease in the total number of people who fell victim to workplace accidents, a $28.5 \%$ decrease in the number of minor injured persons, a $48.5 \%$ decrease in the number of employees injured in severe accidents and a $45 \%$ a decrease in the number of people injured in fatal accidents. 


\subsection{Workplace Accident Frequency Rates}

The research on workplace safety in the civil engineering sector required an analysis of the accident frequency phenomenon using the accident frequency indicator in the years 2004-2018. Figure 5 shows trends of changes in the value of this indicator in total per 1000 persons employed in the sector. Changes in relation to minor, severe and fatal accidents are shown in Figures 6-8. The fifth-degree polynomial describes the studied phenomena well. In all types of workplace accidents, the trend line in the form of the first-degree polynomial exhibits a downward trend.

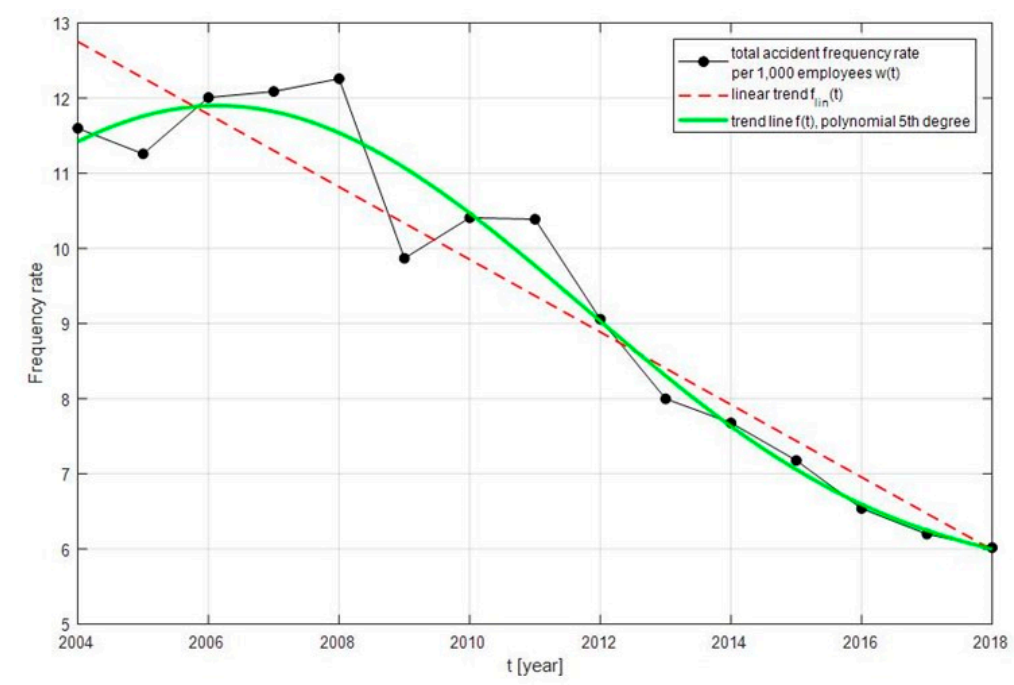

The linear trend of $f_{\text {in }}(t)$ is described by the first-degree polynomial function with the following form $f_{\text {lin }}(t)=-0,4830 t+980,6843$

The trend line $f(t)$ is described as a polynomial function of the fifth-degree with the following form $f(t)=-3,8967 \theta-05 t^{5}+0,3918 t^{4}-1,5756 e+03 t^{3}$

$+3,1683 e+06 t^{2}-3,1855 e+09 t+1,2811 e+12$

Figure 5. Trends of changes in the ratio of the index of the indicator of frequency of total accidents in civil engineering.

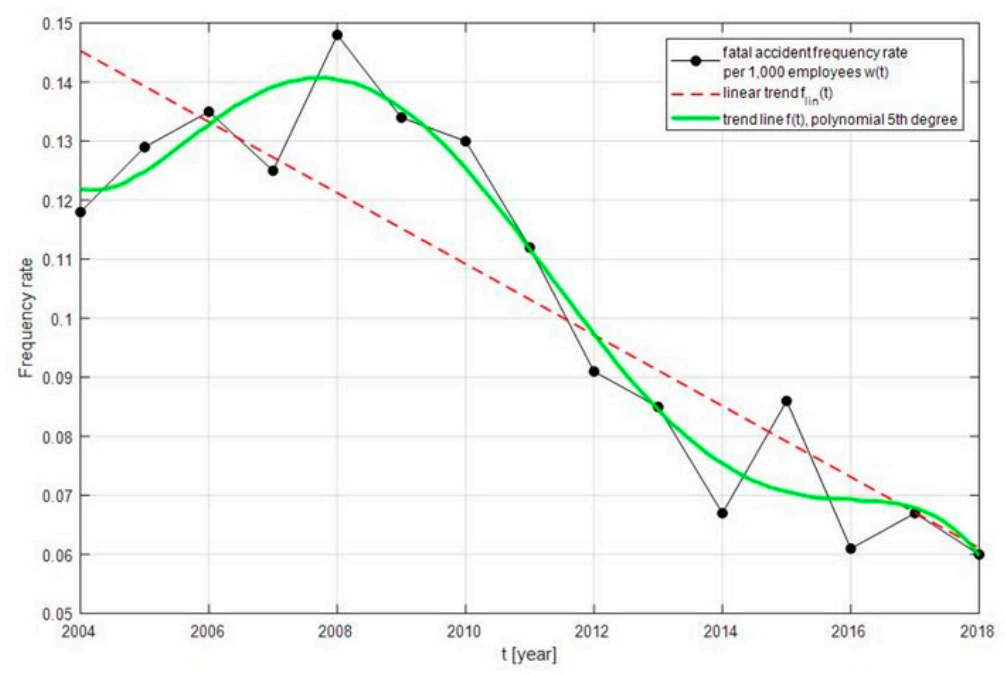

\footnotetext{
The linear trend of $f_{\text {inn }}(t)$ is described by the first-degree polynomial function with the following form $f_{\text {iin }}(t)=-0,0060 t+12,197 \mathrm{~s}$

The trend line $f(t)$ is described as a polynomial function of the fifth-degree with the following form $f(t)=-5,0314 e-06 t^{5}+0,0506 t^{4}-203,4764 t^{3}$$$
+4,0919 e+05 t^{2}-4,1144 e+0 S t+1,6548 e+11
$$

Figure 6. Trends of changes in the frequency of fatal accidents in civil engineering over time. 


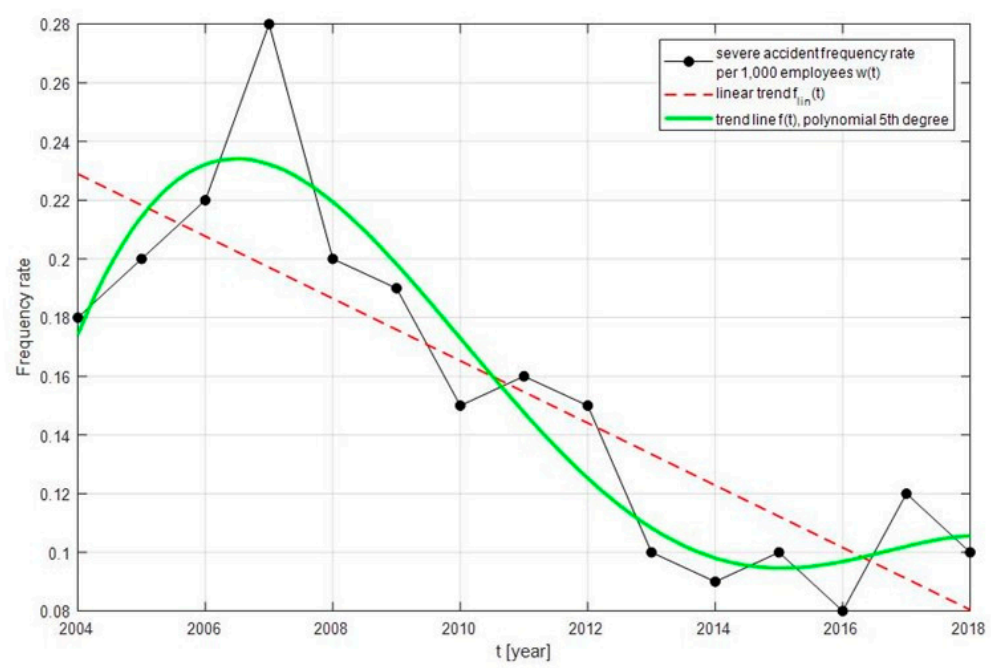

The linear trend of $f_{\text {inin }}(t)$ is described by the first-degree polynomial function with the following form $f_{\text {lin }}(t)=-0,0106 t+21,485 t$

The trend line $f(t)$ is described as a polynomial function of the fifth-degree with the following form

$$
\begin{gathered}
f(t)=-1,4703 e-06 t^{5}+0,0147 t^{4}-59,1831 t^{3} \\
+1,1873 e+05 t^{2}-1,1910 e+05 t+4,7788 e+10
\end{gathered}
$$

Figure 7. Trends of changes in the frequency of severe accidents in civil engineering over time.

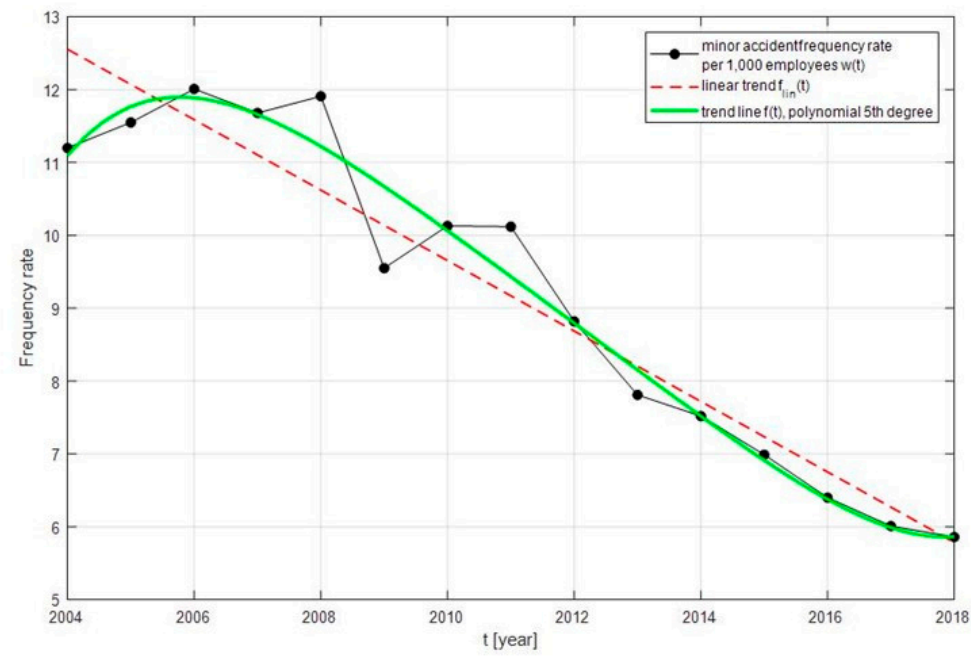

The linear trend of $f_{\text {in }}(t)$ is described by the first-degree polynomial function with the following form $f_{\text {lin }}(t)=-0,4835 t+981,5610$

The trend line $f(t)$ is described as a polynomial function of the fifth-degree with the following form

$$
\begin{gathered}
f(t)=8,2043 e-05 t^{5}-0,8253 t^{4}+3,3204 e+03 t^{3} \\
-6,6799 e+06 t^{2}+6,7191 e+09 t-2,7035 e+12
\end{gathered}
$$

Figure 8. Trends of changes in the frequency of minor accidents in civil engineering over time.

In the period of time analysed, the changes in the value of the total accident frequency indicator, as presented in Figure 7, show a growing tendency until 2008 and then a decrease in the years 2009-2018. The highest value of 12.26 was reached in 2008 . When compared to 2018, when its lowest value 6.02, was recorded representing a decrease of $51 \%$.

Figure 6 shows the changes in the values of the indicators of the frequency of fatal accidents. These exhibit a positive decreasing character. In 2008, the highest value of the indicator was recorded 0.148 , and the lowest 0.06 , in 2018 . This represents a change of $59.5 \%$. 
The severe accident frequency indicator shown in the Figure 7 exhibits a trend with varying degrees of change. In the years 2004-2007, it is growing, but then, in subsequent years, it is decreasing. In 2008, the indicator was 0.148 , the highest value in the analysed period. In relation to 2016, when the lowest value of the indicator was recorded 0.08 , we can observe a $46 \%$ reduction in the phenomenon.

The course of changes in the values of minor accident frequency indicators, presented in Figure 8 , shows a positive decreasing trend. Since 2008, the year with the highest indicator value, 11.91, there has been a systematic decrease in the incidence of minor accidents. In 2018, the indicator reached 5.86, a decrease of $51 \%$ compared to 2008 .

In all investigated types of workplace accidents in the Polish civil engineering sector, there was a significant decrease in the value of workplace accident frequency indicators. Comparing 2004 and 2018 , there was a $49 \%$ decrease in fatal accidents, a $44.5 \%$ decrease in severe accidents and a $47.7 \%$ decrease in minor accidents.

\subsection{Accident Severity Indicator for Work Accidents}

Figure 9 presents the course of changes in the value of the accident severity indicator in the years 2004-2018 and the analytical forms of the trend function. This indicator is well described by the fifth-degree polynomial. The trend line is alternately increasing and then decreasing, and the trend line in the form of the first-degree polynomial shows a downward trend.

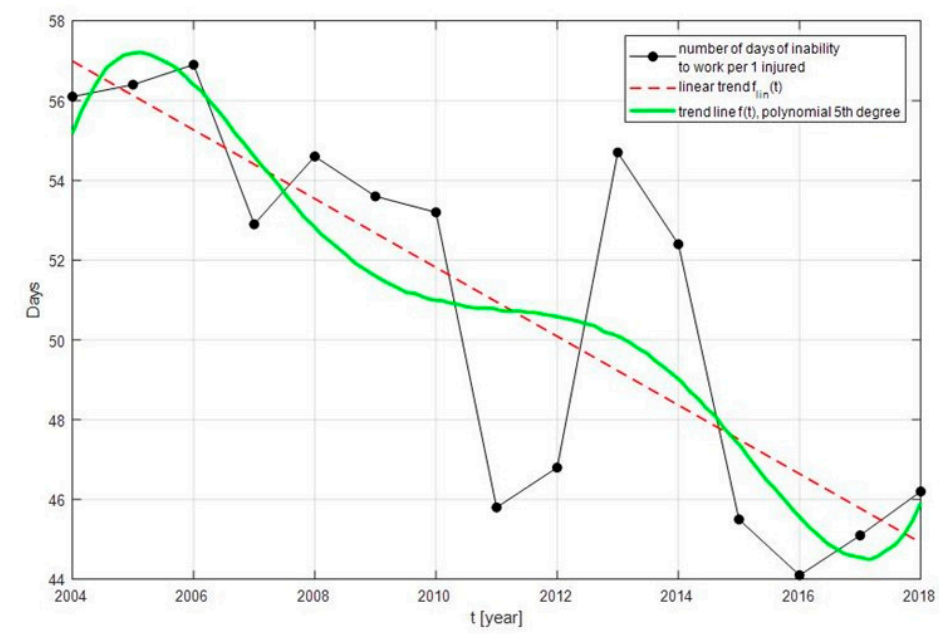

$$
\begin{aligned}
& \text { The linear trend of } f_{\text {in }}(t) \text { is described by the first-degree polynomial function with the following form } \\
& f_{\text {lin }}(t)=-0,8625 t+1,7854 e+03 \\
& \text { The trend line } f(t) \text { is described as a polynomial function of the fifth-degree with the following form } \\
& f(t)=0,0011-11,4575 t^{4}+4,6084 e+04 t^{3} \\
& -9,2680 e+07 t^{2}+9,3194 e+10 t-3,7484 e+13
\end{aligned}
$$

Figure 9. Trends of changes in the seriousness of workplace accidents in civil engineering over time.

By analysing a period of 15 years, it can be observed that the number of days of inability to work resulting from an accident decreased from 56.1 to 46.2 days per one injured person, representing a decrease of $18 \%$.

\section{Discussion and Conclusions}

The conducted research concerning the changes in accident rate in the Polish civil engineering industry and the results of the research presented in the paper allow several important conclusions to be formulated.

Note that the accident rate in the sector analysed of the economy changes over time, meaning that the values of the indicators used to characterise the phenomenon are subject to periodic fluctuations in different time periods. Three types of indicators were selected for the research: The number of people 
injured in workplace accidents including minor, severe and fatal accidents; the frequency index also applicable to all types of accidents; and the severity index of workplace accidents. Assessment of the direction of changes in accident rates as a measure of work safety required the development of a research methodology based on a mathematical model of the development trend of the phenomenon. This made it possible to present the linear trend described by the first-degree polynomial function and the trend line described by the fifth-degree polynomial.

From the analysis of the statistical data for the years 2004-2018, it can be concluded that the changes in accident rate parameters show a continuous improvement in workplace safety. During the 15 years analysed, there was a clear decrease in the value of the applied indicators. This observation applies both to the number of people involved in accidents and to the frequency and severity of accidents. The analysis of the number of people who died in fatal accidents showed a $45 \%$ decrease in 2018 compared to 2004 . For severe accidents, the reduction was $48.5 \%$, and for minor accidents $28.5 \%$.

The indicator showing the number of people involved in an accident was supplemented by the accident frequency indicator in relation to 1000 workers. This indicates the level of occupational risk related to the execution of civil engineering works. The conditions for conducting civil engineering works make the number of threats to health and safety of employees very high. The results of the research, which show a clear downward trend in the frequency of all types of accidents, demonstrate the effectiveness of preventive action taken by employers as well as by supervisors in relation to the working conditions. The comparison of 2018 and 2004 shows a $49 \%$ decrease in the frequency of fatal accidents, including a $44.5 \%$ decrease in serious accidents and a $47.7 \%$ decrease in minor accidents.

The last of the indicators used in the research was the accident severity indicator. It defines the average number of days of incapacity to work resulting from an accident per employee affected. It also identifies the economic losses incurred by employers as a result of accidents. The course of changes in the value of this indicator also shows a decreasing trend. In 2018, it was 5.86, but in 2004 it was 11.2 days, representing a $47.7 \%$ reduction in sickness absences resulting from workplace accidents.

The analysis of the accident rate phenomenon in the Polish construction industry, which makes it possible to assess whether the actions taken so far to reduce the number of accidents have achieved their intended objective, required research using two models of development trends. The first one was the trend function described by the fifth-degree polynomial, which reflected the variability of the phenomenon over time. The second model was the trend function described by the first-degree polynomial, which indicated a general developmental trend in the analysed time period. Studies on the number, frequency and severity of accidents in the Polish construction industry in the years 2004-2018 showed that the situation was improving year by year. This was confirmed by the graphs of changes in the total number of accidents and in relation to 1000 employees. Although periodic increases and decreases in the level of the phenomenon were observed, the trend line in the form of a linear function had a decisive downward trend. Undoubtedly, the improvement of work safety in the Polish construction industry was a consequence of adjusting the Polish law to the EU law in the area of health and safety protection of employees [40,41]. Many significant changes were introduced in the Labour Code [42] and Construction Law [43]. New legal regulations imposed additional obligations on employers and investors. These included assessing occupational risk at the workplace, informing employees about hazards, appointing at least one safety and health coordinator for each construction site where work is carried out by several investors and drawing up a safety and health plan.

The results reported above clearly indicate a constant decreasing trend in the phenomenon of accidents in the civil engineering sector. There has therefore been a gradual improvement in work safety in this section of the economy. Although it does represent an improvement, this nonetheless represents an unsatisfactory situation, since a 'zero accident' situation seems a long way off.

The assessment of accident rates is very important in shaping safe working conditions, as it has an informative and motivational role. It shows the current situation in the civil engineering sector and motivates change for the better. Continuing research in this area is therefore fully justified and desirable. 
Author Contributions: Conceptualization, W.C.; methodology, W.C.; validations, K.A.; formal analysis, W.C. and K.A.; investigation, all authors; data curation, all authors; writing-original draft preparations, W.C. and K.A.; writing - review and editing, all authors; visualization W.C.; project administration, P.S.

Funding: This research received no external funding.

Acknowledgments: Supported by the Foundation for Polish Science (FNP).

Conflicts of Interest: The authors declare no conflict of interest.

\section{References}

1. Yu, Q.Z.; Ding, L.Y.; Zhou, C.; Luo, H.B. Analysis of factors influencing safety management for metro construction in China. Accid. Anal. Prev. 2014, 68, 131-138. [CrossRef] [PubMed]

2. Hoła, B.; Szóstak, M. Analysis of the state of the accident rate in the construction industry in European Union Countries. Arch. Civ. Eng. 2015, 4, 19-34. [CrossRef]

3. Yang, H.; Chew, D.A.; Wu, W.; Zhou, Z.; Li, Q. Design and implementation of an identification system in construction site safety for proactive accident prevention. Accid. Anal. Prev. 2012, 48, 193-203. [CrossRef] [PubMed]

4. Irizarry, J.; Simonsen, K.L.; Abraham, D.M. Effect of Safety and Environmental Variables on Task Durations in Steel Erection. J. Constr. Eng. Manag. 2005, 131, 1310-1319. [CrossRef]

5. Błazik-Borowa, E. Work Safety in Civil Engineering, 1st ed.; Lublin University of Technology: Lublin, Poland, 2015; pp. 111-113.

6. PKD. Regulation of the Council of Ministers of 20 January 2004 on the Polish Classification of Business Activities; Official Journal of 2004 No. 33 item 289. Available online: https://stat.gov.pl/Klasyfikacje/doc/ pkd_04/pkd.htm (accessed on 29 October 2019).

7. EU. Accidents in the Workplace 2004-2018; Statistical Yearbooks GUS; Eurostat: Warszawa, Poland, 2018.

8. Zhou, Z.; Goh, Y.M.; Li, Q. Overview and analysis of safety management studies in the construction industry. Saf. Sci. 2015, 72, 337-350. [CrossRef]

9. Li, X.; Yi, W.; Chi, H.L.; Wang, X.; Chan, A.P. A critical review of virtual and augmented reality (VR/AR) applications in construction safety. Autom. Constr. 2018, 86, 150-162. [CrossRef]

10. Zhang, S.; Sulankivi, K.; Kiviniemi, M.; Romo, I.; Eastman, C.M.; Teizer, J. BIM-based fall hazard identification and prevention in construction safety planning. Saf. Sci. 2015, 72, 31-45. [CrossRef]

11. Malekitabar, H.; Ardeshir, A.; Sebt, M.H.; Stouffs, R. Construction safety risk drivers: A BIM approach. Saf. Sci. 2016, 82, 445-455. [CrossRef]

12. Park, J.; Kim, K.; Cho, Y.K. Framework of automated construction-safety monitoring using cloud-enabled BIM and BLE mobile tracking sensors. J. Constr. Eng. Manag. 2016, 143, 05016019. [CrossRef]

13. Ding, L.Y.; Zhong, B.T.; Wu, S.; Luo, H.B. Construction risk knowledge management in BIM using ontology and semantic web technology. Saf. Sci. 2016, 87, 202-213. [CrossRef]

14. Zhang, S.; Boukamp, F.; Teizer, J. Ontology-based semantic modeling of construction safety knowledge: Towards automated safety planning for job hazard analysis (JHA). Autom. Constr. 2015, 52, 29-41. [CrossRef]

15. Wang, H.-H.; Boukamp, F. Ontology-based representation and reasoning framework for supporting job hazard analysis. J. Comput. Civ. Eng. 2011, 25, 442-456. [CrossRef]

16. Guo, H.; Yu, Y.; Skitmore, M. Visualization technology-based construction safety management: A review. Autom. Constr. 2017, 73, 135-144. [CrossRef]

17. Zhang, S.; Teizer, J.; Lee, J.-K.; Eastman, C.M.; Venugopal, M. Building information modeling (BIM) and safety: Automatic safety checking of construction models and schedules. Autom. Constr. 2013, 29, 183-195. [CrossRef]

18. Newaz, M.T.; Davis, P.R.; Jefferies, M.; Pillay, M. Developing a safety climate factor model in construction research and practice: A systematic review identifying future directions for research. Eng. Constr. Archit. Manag. 2018, 25, 738-757. [CrossRef]

19. Demirkesen, S.; Arditi, D. Construction safety personnel's perceptions of safety training practices. Int. J. Proj. Manag. 2015, 33, 1160-1169. [CrossRef]

20. Wu, C.; Wang, F.; Zou, P.X.; Fang, D. How safety leadership works among owners, contractors and subcontractors in construction projects. Int. J. Proj. Manag. 2016, 34, 789-805. [CrossRef] 
21. Fang, D.; Wu, C.; Wu, H. Impact of the supervisor on worker safety behavior in construction projects. J. Manag. Eng. 2015, 31, 04015001. [CrossRef]

22. Boateng, E.B.; Pillay, M.; Davis, P. Developing a Safety Culture Index for Construction Projects in Developing Countries: A Proposed Fuzzy Synthetic Evaluation Approach. In Proceedings of the International Conference on Applied Human Factors and Ergonomics, Washington, DC, USA, 23-28 July 2019; pp. 167-179. [CrossRef]

23. Guo, B.H.; Yiu, T.W. Developing leading indicators to monitor the safety conditions of construction projects. J. Manag. Eng. 2015, 32, 04015016. [CrossRef]

24. Jo, B.; Lee, Y.; Kim, J.; Khan, R. Trend analysis of construction industrial accidents in Korea from 2011 to 2015. Sustainability 2017, 9, 1297. [CrossRef]

25. Kang, Y.; Siddiqui, S.; Suk, S.J.; Chi, S.; Kim, C. Trends of fall accidents in the US construction industry. J. Constr. Eng. Manag. 2017, 143, 04017043. [CrossRef]

26. Gillen, M.; Goldenhar, L.M.; Hecker, S.; Schneider, S. Safety Culture and Climate in Construction: Bridging the Gap between Research and Practice. In Silver Spring; The Center for Construction Research and Training: Washington, DC, USA, 2014; pp. 1-60.

27. Schwatka, N.V.; Hecker, S.; Goldenhar, L.M. Defining and measuring safety climate: A review of the construction industry literature. Ann. Occup. Hyg. 2016, 60, 537-550. [CrossRef] [PubMed]

28. Hong, J.; Shen, G.Q.; Li, Z.; Zhang, B.; Zhang, W. Barriers to promoting prefabricated construction in China: A cost-benefit analysis. J. Clean. Prod. 2018, 172, 649-660. [CrossRef]

29. Meikandaan, T.P.; Hemapriya, M.; Bist, B. Cost Benefit Analysis of accident prevention in construction industry. Int. J. Pure Appl. Math. 2018, 119, 8831-8842.

30. Tappura, S.; Sievänen, M.; Heikkilä, J.; Jussila, A.; Nenonen, N. A management accounting perspective on safety. Saf. Sci. 2015, 71, 151-159. [CrossRef]

31. Hsu, I.Y.; Su, T.S.; Kao, C.S.; Shu, Y.L.; Lin, P.R.; Tseng, J.M. Analysis of business safety performance by structural equation models. Saf. Sci. 2012, 50,1-11. [CrossRef]

32. Wu, X.; Liu, Q.; Zhang, L.; Skibniewski, M.J.; Wang, Y. Prospective safety performance evaluation on construction sites. Accid. Anal. Prev. 2015, 78, 58-72. [CrossRef]

33. Seo, H.C.; Lee, Y.S.; Kim, J.J.; Jee, N.Y. Analyzing safety behaviors of temporary construction workers using structural equation modeling. Saf. Sci. 2015, 77, 160-168. [CrossRef]

34. Guo, B.H.; Yiu, T.W.; González, V.A. Predicting safety behavior in the construction industry: Development and test of an integrative model. Saf. Sci. 2016, 84, 1-11. [CrossRef]

35. Hinze, J.; Thurman, S.; Wehle, A. Leading indicators of construction safety performance. Saf. Sci. 2013, 51, 23-28. [CrossRef]

36. Grabowski, M.; Ayyalasomayajula, P.; Merrick, J.; Harrald, J.R.; Roberts, K. Leading indicators of safety in virtual organizations. Saf. Sci. 2007, 45, 1013-1043. [CrossRef]

37. Sgourou, E.; Katsakiori, P.; Goutsos, S.; Manatakis, E. Assessment of selected safety performance evaluation methods in regards to their conceptual, methodological and practical characteristics. Saf. Sci. 2010, 48, 1019-1025. [CrossRef]

38. Guo, H.W.; Yiu, T.W. How Traditional Construction Safety Performance Indicators Fail to Capture the Reality of Safety. In Proceedings of the 38th Austrlasian Universities Building Education Association Conference; The University of Auckland: Auckland, New Zealand, 2013.

39. NATLEX. Act of 30 October 2002 on social insurance against workplace accidents and occupational diseases. Dz. Ustaw 2002, 199, 1673.

40. EEC. Directive 89/391/EEC of 12 June 1989 on the Introduction of Measures to Encourage Improvements in the Safety and Health of Workers at Workplace; Official Journal L 183, 29/06/1989. Available online: https:/eur-lex.europa.eu/legal-content/EN/TXT/?qid=1572261254385\&uri=CELEX:31989L0391 (accessed on 29 October 2019).

41. EEC. Directive 92/57/EEC of 24 June 1992 on the Implementation of Minimum Safety and Health Requirements at Temporary or Mobile Construction Sites; Official Journal L 245, 26.08.1992. Available online: https: //eur-lex.europa.eu/legal-content/EN/TXT/?qid=1572261331993\&uri=CELEX:31992L0057 (accessed on 29 October 2019). 
42. Act of 26 June 1974-Labour Code (i.e., Official Journal 2019 Item 1040). Available online: http://prawo.sejm. gov.pl/isap.nsf/download.xsp/WDU19740240141/U/D19740141Lj.pdf (accessed on 29 October 2019).

43. Act of 7 July 1994-Construction Law (i.e., Official Journal 2019 Item 1186). Available online: http://prawo. sejm.gov.pl/isap.nsf/download.xsp/WDU19940890414/U/D19940414Lj.pdf (accessed on 29 October 2019). 